\title{
Linguistic innovation among Glasgow Gaelic new speakers
}

\author{
Claire Nance \\ Department of Linguistics and English Language, Lancaster University
}

\section{Introduction}

An increasingly wide body of literature has examined the ideological practices surrounding new speakers, and attitudes to their varieties (for example Puigdevall 2014; O’Rourke, Pujolar \& Ramallo 2015; O’Rourke \& Pujolar 2015). Less studied, however, are the linguistic forms used by new speakers. A central aim of the new speaker model is to conceptually move away from the notions of deficiency implied by such terms as 'non-native' 'second language' and 'learner' (O'Rourke \& Ramallo 2013, 56). Much of the previous work on new speakers has considered this aim employing a qualitative examination of power distribution.

Another potential angle is to quantitatively investigate the linguistic forms used by new speakers. In doing so I aim to demonstrate that while the linguistic behaviour of new speakers may be different to traditional forms of the language, it has its own internal consistency, and can be considered as innovative rather than deficient. Specifically, this chapter firstly considers how linguistic forms used by new adolescent Scottish Gaelic speakers in Glasgow are innovative compared to traditional varieties of Gaelic. Secondly, I consider the extent to which we can consider new speaker varieties as new dialects of minority languages. In the remainder of this section I discuss previous quantitative linguistic studies of young people in immersion schooling and provide some background to the context of Gaelic in Glasgow. Section 2 presents an analysis of three phonetic features: tone and 
intonation, vowels and laterals. Section 3 discusses some of the growing recognition of Glasgow Gaelic as a distinct variety, and the extent to which it may develop further in the future. In this section I also discuss the wider Glasgow Gaelic community, including ongoing research with adult new speakers (see McLeod \& O'Rourke 2015).

Some previous studies have considered the speech of young speakers in revitalisation programmes, though these are not explicitly conducted within the new speaker framework. For example, it is noted that young Irish speakers in immersion schooling sound different to traditional speakers (Ó Curnáin 2007; Ó Giollagáin, Mac Donnacha, Ní Chualáin et al. 2007). Specifically, complex phonemic systems such as the triple lateral system in Irish are sometimes not produced (Maguire 1991). Similarly, morphological structures which are different to the community-dominant language might not be reproduced (Ravid 1995; Jones 1998; Ó Duibhir \& Garland 2010). Studies of Japanese immersion students, Maori young speakers and Welsh immersion students have noted phonetic transfer from the community-dominant language (Harada 2006; King, Watson, Keegan et al. 2009; Morris 2013 respectively). Some of these studies have cited differences between young people who speak the language in question at home, and those who do not. For example, Morris (2013) found that young people who had two Welsh-speaking parents behaved differently to those who did not (see also Gathercole \& Thomas 2009). Similarly, a wide body of literature on sociolinguistic variation in Canadian French suggests that those immersion students with more contacts in the French-speaking community are more likely to reproduce typical patterns of sociolinguistic variation (for example Mougeon, Rehner \& Nadasdi 2004; Nadasdi, Mougeon \& Rehner 2005). 
The above literature suggests that teenagers in Gaelic medium schooling in Glasgow may speak differently to traditional forms of Gaelic. Historically, Gaelic has not been spoken in Glasgow as a community language. However, there has been a long tradition of Gaelic speakers migrating to the city from the Highlands and Islands (Withers 1998), and Gaelic has been used in certain networks of Highland migrants and their descendants for several hundred years (see, for example, Kidd, 2007 for discussion of the network and cultural use of Gaelic in Glasgow). Recently, Glasgow has become home to an increasingly important percentage of the total number of Gaelic speakers, with the 2011 census recording that about $17 \%$ of Gaelic speakers live in the Greater Glasgow area. Glasgow still attracts Gaelic-speaking migrants from the Highlands and Islands, especially with the increase in Gaelic-essential jobs due to revitalisation measures, but the city is also home to a large number of new speakers, both adults and immersion school pupils (McLeod, O'Rourke \& Dunmore 2014; McLeod \& O'Rourke 2015; Nance 2015b). Glasgow is especially significant in terms of Gaelic-medium education: it was the location of one of the first two Gaelicmedium primary schools, founded in 1999, and is still the location of the only Gaelicmedium secondary school. At all other facilities offering Gaelic-medium secondary education, a Gaelic-medium stream exists within an otherwise English-medium school (MacLeod 2003).

While previous work has suggested that traditional Gaelic dialects are extremely diverse (for example Ó Dochartaigh 1997), there is some suggestion that this diversity is being lost as a result of Gaelic revitalisation (Lamb 2011). Previous work has not considered the possibility of new varieties emerging in cities; rather, it has focused on the loss of traditional varieties. Here I examine the extent to which we can discuss a 
new variety among new speakers. The question of how and why new varieties arise has been extensively studied in the sociolinguistic literature, either from the perspective of koineisation in new communities of mutually intelligible dialects (for example Siegel 1985; Kerswill \& Williams 2000; Lane 2000; Gordon, Campbell, Hay et al. 2004; Trudgill 2004; Kerswill \& Williams 2005), or from the perspective of the emergence of multicultural varieties in urban European contexts (for example Kotsinas 1988; Quist 2008; Wiese 2009; Cheshire, Kerswill, Fox et al. 2011). The discussion section of this paper explores the extent to which such studies are relevant to the context of Gaelic in Glasgow and whether a similar process of new dialect formation might be occurring.

\section{Analysis}

The data used in this chapter are from interviews and participant observation conducted in 2010-2011. Here, I present analysis of interview data from twenty-one teenagers in Gaelic medium secondary education in Glasgow. They are compared to twelve teenagers of the same age living in a Gaelic-speaking heartland area, the Isle of Lewis, and to six older Gaelic-speakers (aged 60-86) who grew up in almost entirely Gaelic-speaking environments. From the Glasgow sample, only three young people grew up speaking Gaelic to one parent, the rest coming from backgrounds with limited Gaelic among the grandparents, or no Gaelic-speaking background at all. Apart from some limited use of Gaelic in their homes then, the Glasgow teenagers had mainly acquired Gaelic from their immersion schooling experience and can be considered new speakers. All pupils reported feeling 'more comfortable' in English, and they used English among themselves during social time at school, in Englishmedium classes, and sometimes during Gaelic-medium classes as well. In terms of 
their home life, the participants came from a range of Glasgow suburbs from largely middle class backgrounds (see also O'Hanlon, Paterson \& McLeod 2010 for further detail on the social class backgrounds of Gaelic medium pupils).

The young people from Lewis discussed in this chapter experienced more Gaelic usage in their wider community by virtue of living in a traditional Gaelic heartland area. However, only three of them reported speaking Gaelic to one of their parents (none spoke Gaelic to both parents), and they typically used English among themselves at school. A summary of the participants discussed in this chapter is in Table 1; for further information on the participants' backgrounds, language use, and Gaelic acquisition trajectories, see Nance $(2013,2015 b)$.

\begin{tabular}{lllll}
\hline Gender & Glasgow & Lewis young & Lewis old & Total \\
\hline Female & 12 & 6 & 3 & 21 \\
Male & 9 & 6 & 3 & 18 \\
Total & 21 & 12 & 6 & 39 \\
\hline
\end{tabular}

Table 1: Total participants in this study.

In this chapter I consider three aspects of the phonetic system and discuss the extent to which new speakers in Glasgow demonstrate behaviour which is divergent from their age-equivalent counterparts in a heartland community on the one hand and which is also divergent from older traditional speakers in a heartland community on the other. The linguistic features considered are tone and intonation; the vowel /u/; and lateral phonemes. 


\subsection{Tone and intonation}

Many traditional varieties of Gaelic, including the Lewis dialect, are described as 'pitch accent' languages, which make some use of lexical tone (Borgstrøm 1940; Oftedal 1956; Dorian 1978; Ladefoged, Ladefoged, Turk et al. 1998; Ternes 2006; Iosad 2014; Nance 2015a). In the relevant Gaelic dialects, a contrast is made in accented words according to the number of syllables in the word: monosyllabic words are realised with a low or rising pitch, and polysyllabic words are realised with a high, falling, or rising-falling pitch. My previous work showed that while this system is used extremely consistently by the older speakers in Lewis, it is not used at all by young people in Lewis, or young Glaswegians (Nance 2015a). Here, instead of focussing on non-existent lexical tones, I consider the sentence-level intonation patterns used by young speakers in Glasgow, and how these differ from the intonation contours used by young Lewis speakers.

Descriptions of Glasgow English intonation state that intonation is most commonly rising, and that phrase-final contours can be described as a 'rise plateau' or 'rise plateau slump' (Mayo 1996; Cruttenden 2007; Ladd 2008). An example of the 'rise plateau' contour in Gaelic is shown on the left of Figure 1. Approximately thirty intonation phrases per speaker were extracted from the middle ten minutes of each interview. Intonation phrases (IPs) were selected from those conveying one of two pragmatic functions: either narratives or general accounts, as defined in the Discourse Context Analysis framework (Gregersen, Nielsen \& Thøgersen 2009).

These IPs were prosodically labelled in Praat (Boersma \& Weenik 2014) using the labelling system known as IViE (Intonational variation in English) (Grabe, Nolan \& 
Farrar 1998). Here, I consider penultimate (prenuclear) and phrase-final (nuclear) pitch accents. Pitch accents are prosodically prominent syllables. Pitch accents usually occur on stressed syllables, but stressed syllables are not always pitchaccented (Ladd 2008). Penultimate and phrase-final pitch accents were labelled using IViE, and I here consider the two most commonly occurring pitch accents:

penultimate $\mathrm{H}^{*}+\mathrm{L}$ (simple fall) and $\mathrm{L}^{*}+\mathrm{H}$ (simple rise); and phrase-final $\mathrm{H}^{*}$ $+\mathrm{L} 0 \%$ (simple fall) and $\mathrm{L}^{*}+\mathrm{H} 0 \%$ (rise plateau/rise plateau slump). I refer to the pitch accents using their descriptive labels (rise, fall) for clarity. In this analysis, the coding of penultimate and phrase-final contours are combined into one: penultimate rises and phrase-final rise plateaux are referred to as rise; and penultimate falls and phrase-final fall plateaux are referred to as fall. In total, 2,090 pitch accents are analysed.

The results are shown on the right of Figure 1. A mixed effects logistic regression model comparing the number of rises to the number of falls showed that there were significantly fewer rises in Lewis than in Glasgow $(\beta=-3.45, p<0.001)$. There were no differences according to gender. Having a Gaelic-speaking parent did significantly correlate with the results: Glasgow young speakers who spoke Gaelic to one parent had significantly fewer rising contours than those who did not $(\beta=-2.67, p<0.001)$. 


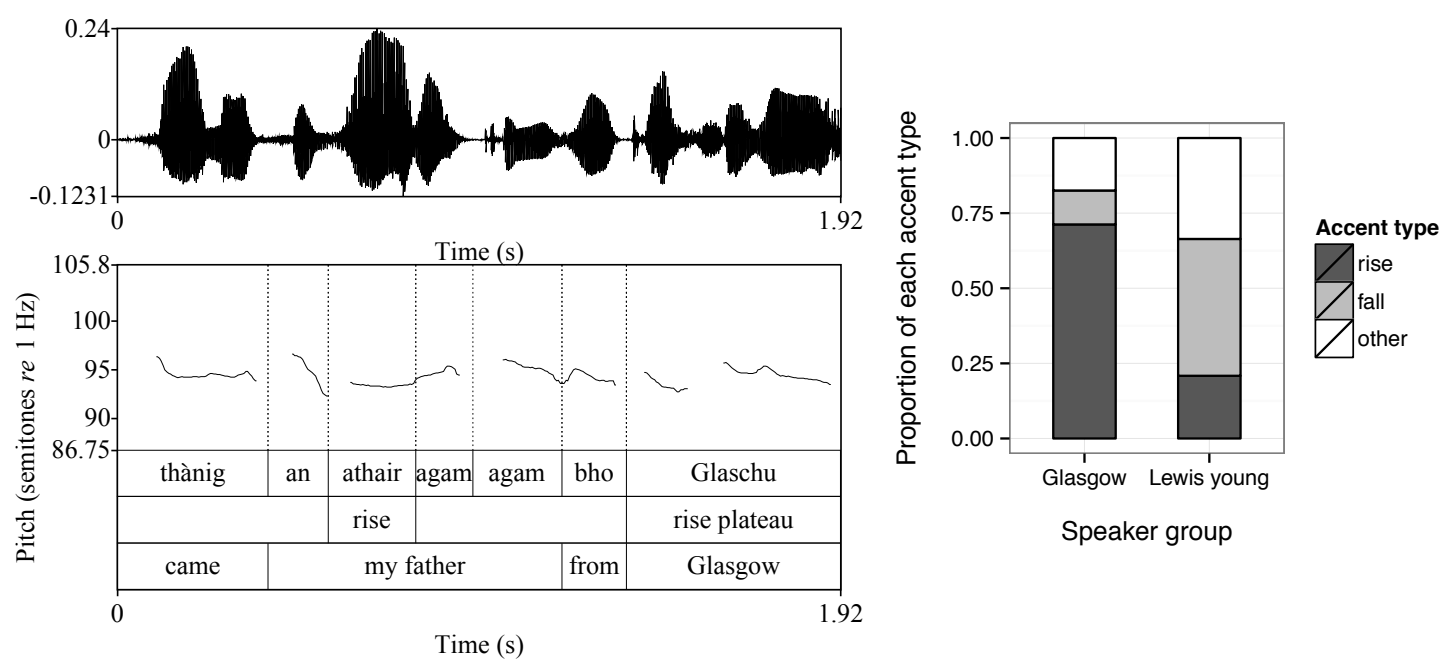

Figure 1: Left panel: sample spectrograms and waveform from the dataset showing a Glaswegian 'rise plateau' contour. Right panel: Results of the intonational coding.

\subsection{Vowel /u/}

Gaelic has an interesting and diverse system of back vowels (Ladefoged, Ladefoged, Turk et al. 1998; Nance 2011). Previous work has noted that the vowel /u/ has two distinct allophones: $[\mathrm{u}]$ in the environment of velarised consonants, and central $[\mathrm{u}]$ elsewhere. This section considers variation in the $[\mathrm{H}]$ allophone only. While research on $/ \mathrm{u} /$ in the English-speaking world has largely noted that the vowel is more front acoustically (having a higher second formant) for young speakers (for example Harrington 2007; Mesthrie 2010; Cheshire, Kerswill, Fox et al. 2011), recent work among English-speakers in Glasgow suggests the opposite: /u/ is in fact backer among younger generations. It is hypothesised that in Scottish English /u/ is already very front indeed so has reached the limits of its fronting potential and has begun to move backwards in the acoustic space (Rathcke, Stuart-Smith, Timmins et al. 2012). It is therefore interesting to consider the situation in Gaelic as spoken by Glaswegians. 
For this part of the study, relevant tokens of $[\mathrm{u}]$ were extracted from the interviews for all speakers, and I also extracted ten tokens each of /i/ and /a/ for normalisation purposes. Measures of the first two formants were extracted at the peak F2 values in the middle $50 \%$ duration of the vowel (Harrington 2010, 180). The data were then auditory scaled to Bark (Traunmüller 1990) and normalised using Lobanov normalisation (Lobanov 1971). In order to assess whether a token was 'front' in acoustic space, the $\mathrm{F} 2$ of each $[\mathrm{H}]$ token was subtracted from each speaker's average $\mathrm{F} 2$ value for /i/. This results in a measure which I refer to as ' $\mathrm{F} 2$ distance'.

Vowel plots showing the results are shown in Figure 2. The ellipses show 95\% confidence intervals around the data. A mixed effects linear regression model on F2 distance suggests that Lewis young and Lewis older speakers have a significantly lower F2 distance (fronter $[\mathrm{u}]$ ) compared to Glasgow speakers (Lewis young: $\beta=-$ $0.62, p=0.002$; Lewis older: $\beta=-1.92, p<0.001)$. Of the three groups of speakers, Lewis older speakers therefore have the frontest productions, and Glasgow young speakers have the backest productions.
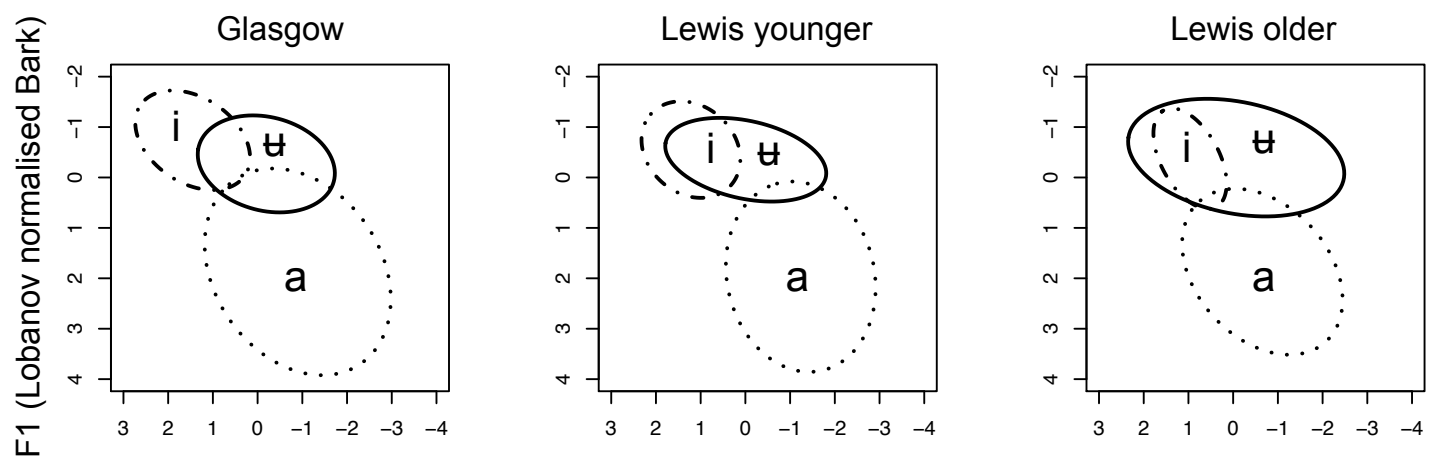

F2 (Lobanov normalised Bark)

Figure 2: Vowel plots showing the formant values for each speaker group. 


\subsection{Laterals}

In this section, I consider the linguistic behaviour of Glasgow new Gaelic speakers with respect to lateral phonemes. Previous work has identified three phonemic laterals in Gaelic (Borgstrøm 1940; Oftedal 1956; Shuken 1980; Ladefoged, Ladefoged, Turk et al. 1998; Nance 2014). These are a dental lateral with velarisation, an alveolar lateral, and a dental lateral with palatalisation $/ \underset{n}{\mathrm{l}} 1 \mathrm{j} \mathrm{j} /$. I refer to these as velarised, alveolar, and palatalised respectively. The differences between the laterals can be captured acoustically by measuring the difference between the first two formants: the velarised lateral has the lowest F2-F1, and the palatalised lateral the highest F2-F1 (Ladefoged, Ladefoged, Turk et al. 1998; Nance 2014). From the point of view of this chapter, this triple lateral system in Gaelic is extremely interesting as it is so different from the single lateral reported for Glaswegian English, which is reportedly velarised or pharyngealised in all syllable positions (Wells 1982; Stuart-Smith 1999).

In order to investigate the laterals in Gaelic, I conducted a study of a set of word list data collected from the participants. Three older Lewis male speakers did not participate in the word-list study as they could not read Gaelic; and one female young Lewis speaker did not complete the word-list task. This analysis therefore considered data from thirty-five speakers in total. The word list considers word initial and word medial laterals in near-minimal triplets (see Nance 2013, 2014, 2015b for more methodological details). Measurements of the first two formants were taken at the temporal mid-point of the lateral steady-state (Carter \& Local 2007). 
Mixed effects linear regression modelling was conducted on the F2-F1 dependent variable. Glasgow speakers were set as the baseline so that the model could demonstrate how the Lewis speakers diverged from the Glaswegians. Overall, the model shows that alveolar and palatalised laterals are significantly different from velarised laterals, indicating that, considering the dataset as a whole, the lateral phonemes are phonetically distinct (alveolar: $\beta=1.68, p=0.005$; palatalised: $\beta=$ $3.42, p<0.001)$. There are significant interactions between Lewis young speakers and $\operatorname{alveolar}(\beta=1.62, p<0.001)$ and palatalised laterals $(\beta=1.88, p<0.001)$, and interactions between Lewis older speakers and alveolar $(\beta=4.71, p<0.001)$ and palatalised laterals ( $\beta=4.70, p<0.001$ ). These data are displayed in Figure 3, and show that Glasgow speakers have lower F2-F1 than both groups of Lewis speakers in both alveolar and palatalised laterals.

The significant findings for the alveolar and palatalised laterals suggest that Glasgow young people are producing laterals that are more velarised/pharyngealised than speakers from Lewis. This may be due to the influence of the lateral in Glasgow English, which is reportedly velarised/pharyngealised (Wells 1982; Stuart-Smith 1999). In the (phonemically) velarised lateral data, Glasgow speakers were no different to the Lewis young people, suggesting that their already-velarised productions aligned with typical Gaelic productions in this sound. 

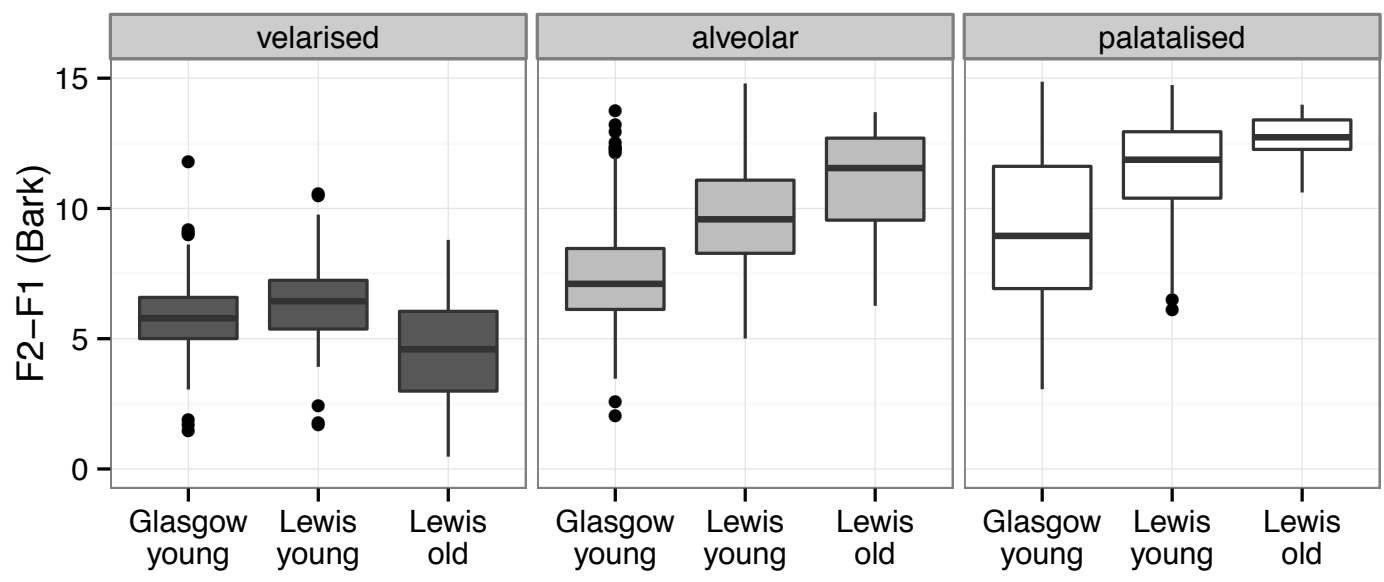

Figure 3: F2-F1 values for each lateral in each speaker group.

\subsection{Summary}

The above data suggest that Gaelic as spoken by teenagers in Glasgow is different from the Gaelic of young and older Lewis speakers in several ways. First, Glasgow speakers make extensive use of phrase-final rising intonation contours, which are different from the intonation used by their age-equivalent counterparts in Lewis. It seems likely that this rising intonation is the result of cross-language transfer from Glasgow English as described by Mayo (1996); Cruttenden (2007); and Ladd (2008). Second, Glasgow Gaelic has a backer $[\mathrm{u}]$ vowel than either Lewis younger or Lewis older speakers. Again, this is probably due to the influence of the middle class variety of Glasgow English spoken by the young people in this study. Middle class Glaswegian English has been described as having an increasingly backed $[\mathrm{u}]$ in the most recent work on this vowel (Rathcke, Stuart-Smith, Timmins et al. 2012). Finally, I considered lateral phonemes. The regression modelling on the lateral data suggested that Glasgow speakers had significantly more velarised/pharyngealised productions than the Lewis speakers in the alveolar and palatalised laterals. They were no different in the velarised category, perhaps because their typical laterals are already 
velarised, which happens to coincide with the realisation of this category in Lewis Gaelic. In summary, the Glaswegian young people in this study speak Gaelic in a quantitatively different manner to both their age-equivalent counterparts in Lewis, and to older traditional speakers in Lewis. Not only is their Gaelic different, but it is different in a Glaswegian way.

\section{Discussion and conclusions}

The data above suggest that young new speakers in Glasgow speak a Glaswegianflavoured variety of Gaelic. Given the previous work on phonetic variation among new speakers discussed in Section 1, this result is perhaps unsurprising, but suggests that Gaelic is being adapted for new contexts and new groups of speakers. In the section that follows, I will consider whether this distinctive Glaswegian-influenced variety can be considered as a new dialect.

The linguistic analysis in this chapter suggests that Gaelic as spoken in Glasgow is linguistically different from traditional varieties. However, the nature of what constitutes a distinct variety is also necessarily socially constructed to a certain extent. There is some evidence to suggest that this kind of Gaelic is being recognised as distinctive and innovative within Gaelic-speaking circles. For example, Joseph's (2013) study explores the social construction of 'Glasgow Gaelic' and suggests that is it increasingly identified as an innovative variety in the community. The speakers reported here also identified their Gaelic as Glaswegian influenced and different from traditional kinds of Gaelic. Short extracts from two Glasgow young female speakers illustrating this point are shown below. The speaker in the first extract suggests that the young people in the Glasgow school have a different, and more Glaswegian, 
accent to their teachers from traditional dialect areas. Similarly, the speaker in the second extract suggests that her kind of Gaelic is influenced by her Glaswegian English. See Nance (2015b) for analysis and further discussion.

\section{Extract 1}

Tha mar like na tidsearan tha na accents Like the teachers they have different acasan diofraichte chionns gu bheil accents because they're from up [there] iadsan a' tighinn bho suas bho na h- from the Islands

Eileanan

ach mar tha na accents aig mar like na but like the pupils' accents they're like sgoilearan diofraichte chionns gu bheil different because we're from Glasgow sinne bho like Glaschu agus àitichean and places down here. sìos an seo.

\section{Extract 2}

Tha mi dìreach a' smaointinn gu bheil I just think I speak like [I do] in English, mi a' bruidhinn mar ann am Beurla ach but in Gaelic. ann an Gàidhlig.

There is a substantial amount of sociolinguistic literature on the formation of new dialects (for example Kerswill \& Williams 2000; Lane 2000; Gordon, Campbell, Hay et al. 2004; Trudgill 2004; Kerswill \& Williams 2005). However, this body of work considers new dialect formation to occur when migrants of mutually intelligible varieties of the same language move to a new area, either through colonisation, as in New Zealand (Gordon, Campbell, Hay et al. 2004; Trudgill 2004), or through 
building new towns (Kerswill \& Williams 2000; Lane 2000; Kerswill \& Williams 2005). Over subsequent generations the new variety stabilises and becomes the native language of children born in the community, in a process known as koineisation (Siegel 1985). The case of Glasgow Gaelic as described in this paper is clearly not the same social context. The teenagers described here rarely use Gaelic outside of their school environment, and although their variety is linguistically different to other kinds of Gaelic and is beginning to be recognised in the wider community, it seems unlikely that it will be koineised in a similar fashion to New Zealand English, for example. The New Zealand context discussed above showed how this distinctive kind of English stabilised over subsequent generations of New Zealanders. In the context of Gaelic in Glasgow as described here, the young people in the school do not represent a huge number of speakers (like the thousands colonising New Zealand), and may or may not continue to use the language or even pass on their Gaelic to subsequent generations (see Dunmore, 2014).

Further understanding could perhaps be gained from investigating the case of adult Gaelic- speakers in Glasgow. Ongoing research on this topic (McLeod, O'Rourke \& Dunmore 2014; McLeod \& O’Rourke 2015; Nance, McLeod, O’Rourke \& Dunmore 2016) suggests that while there are some Gaelic-speaking migrants coming to Glasgow in a way which could potentially parallel the cases described above, the numbers are not significant enough for koineisation to take place. Instead, a growing community of adult new speakers play an important role in what can be considered as the Glasgow Gaelic-speaking community. Analysis of their phonetic behaviour (Nance et al. 2016), suggests that so far there is little evidence of a consistent group 
variety developing. Instead there is substantial individual variation, which can be linked to explicit and implicit aims of what it means to be a new Gaelic speaker.

So far, this chapter has identified some development of a new way of speaking among new Gaelic-speaking teenagers in Glasgow. Their variety has some increasing social recognition as both linguistically different and distinctly Glaswegian, yet as noted in much of the new speaker literature, new varieties may have some way to go before being universally recognised as a 'legitimate' and 'authentic' way of speaking (O'Rourke \& Ramallo 2013; Ortega et al. 2014; McLeod \& O'Rourke 2015). From the above discussion, it is clear that the variety of Gaelic found in Glasgow cannot be considered as 'new dialect formation' as it has previously been described in the literature. Similarly, the previous definition of 'new dialect formation' does not fit what is taking place among adult Gaelic speakers in Glasgow. On the one hand therefore, there is a linguistically and socially distinct way of speaking Gaelic emerging in Glasgow; on the other hand, this new way of speaking does not fit previous sociolinguistic models of what is considered a new dialect. However, this is not an ephemeral social phenomenon: Gaelic medium education and adult learning is increasing in Glasgow and although the new speaker community does not fit previous models of a new dialect, it appears that the variety may increase in terms of number of speakers, even if the teenagers in this study do not pass Gaelic on to their children. I would like to suggest that something which can be called 'Glasgow Gaelic' is a growing social phenomenon, and the fascinating context of new speakers can contribute new data to previous theories of community structure and the development of new varieties in the sociolinguistic literature. 


\section{References}

Boersma, Paul \& Daniel Weenik. 2014. Praat: Doing phonetics by computer [computer program]. Version 5.4.04. URL http://www.praat.org/.

Borgstrøm, Carl. 1940. The dialects of the Outer Hebrides, vol. 1. Olso: Norsk Tidsskrift for Sprogvidenskap.

Carter, Paul \& John Local. 2007. F2 variation in Newcastle and Leeds English liquid systems. Journal of the International Phonetic Association 37(2), 183- 199.

Cheshire, Jenny, Paul Kerswill, Sue Fox \& Eivind Torgersen. 2011. Contact, the feature pool and the speech community: The emergence of Multicultural London English. Journal of Sociolinguistics 15(2), 151-196.

Cruttenden, Alan. 2007. Intonational diglossia: A case study of Glasgow. Journal of the International Phonetic Association 37(3), 257-274.

Dorian, Nancy. 1978. East Sutherland Gaelic: The dialect of the Brora, Golspie, and Embo fishing communities. Dublin: Dublin Institute for Advanced Studies.

Dunmore, Stuart. 2014. Bilingual life after school? Language use, ideologies and attitudes among Gaelic-medium educated adults. Ph.D. thesis, University of Edinburgh, Edinburgh.

Gathercole, Virginia Mueller \& Enlli Môn Thomas. 2009. Bilingual first language development: Dominant language takeover, threatened minority language takeup. Bilingualism: Language and Cognition 12(2), 213-237.

Gordon, Elizabeth, Lyle Campbell, Jennifer Hay, Margaret Maclagan, Andrea Sudbury \& Peter Trudgill. 2004. New Zealand English: its origins and evolution. Cambridge: Cambridge University Press.

Grabe, Esther, Francis Nolan \& Kimberley Farrar. 1998. IViE - A comparative transcription system for intonational variation in English. In Proceedings of 
the 5th International Conference on Spoken Language Processing, 12591262, Sydney, Australia.

Gregersen, Frans, Søren Beck Nielsen \& Jacob Thøgersen. 2009. Stepping into the same river twice on the discourse context analysis in the LANCHART project. Acta Linguistica Hafniensia 41, 30-63.

Harada, Tetsuo. 2006. The acquisition of single and geminate stops by Englishspeaking children in a Japanese immersion program. Studies in Second Language Acquisition 28, 601-632.

Harrington, Jonathan. 2007. Evidence for a relationship between synchronic variability and diachronic change in the Queen's annual Christmas broadcasts. In John Cole \& José Hualde (eds.) Laboratory Phonology IX, 125-143, Berlin: Mouton de Gruyter.

Harrington, Jonathan. 2010. Phonetic analysis of speech corpora. Oxford: WileyBlackwell.

Iosad, Pavel. 2014. 'Pitch accent' and prosodic structure in Scottish Gaelic: Reassessing the rôle of contact. In Martin Hilpert, Janet Duke, Christine Mertzlufft, Jan-Ola Östman \& Michael Rießler (eds.) Advances in Nordic linguistics, Berlin: Mouton de Gruyter.

Jones, Mari. 1998. Language obsolescence and revitalization: Linguistic change in two sociolinguistically contrasting Welsh communities. Oxford: Clarendon Press.

Joseph, John. 2013. Alien species: the discursive othering of grey squirrels, Glasgow Gaelic, Shetland Scots and the gay guys in the shag pad. Language and Intercultural Communication 13(2), 182-201. 
Kerswill, Paul \& Ann Williams. 2000. Creating a New Town koine: Children and language change in Milton Keynes. Language in Society 29, 65-115.

Kerswill, Paul \& Ann Williams. 2005. New towns and koineisation: Linguistic and social correlates. Linguistics 43(5), 1023-1048.

King, Jeanette, Catherine Watson, Peter Keegan \& Margaret Maclagan. 2009.

Changing pronunciation in the Maori language: Implications for revitalization. In John Rehner \& Louise Lockard (eds.) Indigenous language revitalization: Encouragement, guidance and lessons learned, 85-96, Flagstaff, Arizona: Northern Arizona University.

Kotsinas, Ulla-Brit. 1988. Immigrant children's Swedish - a new variety? Journal of Multilingual and Multicultural Development 9(1-2), 129-140.

Ladd, D. Robert. 2008. Intonational phonology. Cambridge: Cambridge University Press, 2nd edn.

Ladefoged, Peter, Jenny Ladefoged, Alice Turk, Kevin Hind \& St John Skilton. 1998. Phonetic structures of Scottish Gaelic. Journal of the International Phonetic Association 28, 1-41.

Lamb, Will. 2011. Is there a future for regional dialects in Scottish Gaelic? Oral paper presented at the FRLSU Colloquium.

Lane, Lisa Ann. 2000. Trajectories of linguistic variation: Emergence of a dialect. Language Variation and Change 12, 267-294.

Lobanov, B. 1971. Classification of Russian vowels spoken by different speakers. Journal of the Acoustical Society of America 49, 606-608.

MacLeod, Donald. 2003. An historical overview. In Margaret Nicolson \& Matthew MacIver (eds.) Gaelic medium education, Edinburgh: Dunedin Academic Press. 
Maguire, Gabrielle. 1991. Our own language: An Irish initiative. Clevedon: Multilingual Matters.

Mayo, Catherine. 1996. Prosodic transcription of Glasgow English: An evaluation of GlaToBI. Master's thesis, University of Edinburgh, Edinburgh.

McLeod, Wilson \& Bernadette O’Rourke. 2015. “New speakers” of Gaelic: Perceptions of linguistic authenticity and appropriateness. Applied Linguistics Review 6(2), 151-172.

McLeod, Wilson, Bernadette O'Rourke \& Stuart Dunmore. 2014. 'New Speakers' of Gaelic in Edinburgh and Glasgow. Soillse, URL http://www. soillse.ac.uk/en/publications/communities/.

Mesthrie, Rajend. 2010. Socio-phonetics and social change: Deracialisation of the GOOSE vowel in South African English. Journal of Sociolinguistics 14(1), 333.

Morris, Jonathan. 2013. Sociolinguistic variation and regional minority language bilingualism: an investigation of Welsh-English bilinguals in North Wales. Ph.D. thesis, University of Manchester, Manchester.

Mougeon, Raymond, Katherine Rehner \& Terry Nadasdi. 2004. The learning of spoken French variation by immersion students from Toronto, Canada. Journal of Sociolinguistics 8(3), 408-432.

Nadasdi, Terry, Raymond Mougeon \& Katherine Rehner. 2005. Learning to speak everyday (Canadian) French. The Canadian Modern Language Review 61(4), $543-561$.

Nance, Claire. 2011. High back vowels in Scottish Gaelic. In Proceedings of the 17th International Congress of the Phonetic Sciences, Hong Kong: City University Hong Kong. 
Nance, Claire. 2013. Phonetic variation, sound change, and identity in Scottish Gaelic. Ph.D. thesis, University of Glasgow, Glasgow.

Nance, Claire. 2014. Phonetic variation in Scottish Gaelic laterals. Journal of Phonetics 47, 1-17.

Nance, Claire. 2015a. Intonational variation and change in Scottish Gaelic. Lingua $160,1-19$.

Nance, Claire. 2015b. 'New' Scottish Gaelic speakers in Glasgow: A phonetic study of language revitalisation. Language in Society 44, 1-27.

Nance, Claire, Wilson McLeod, Bernadette O'Rourke \& Stuart Dunmore. Forthcoming 2016. Identity, accent aim, and motivation in second language users: New Scottish Gaelic speakers' use of phonetic variation. Journal of Sociolinguistics.

Ó Curnáin, Brian. 2007. The Irish of Iorras Aithneach, County Galway. Dublin: Dublin Institute for Advanced Studies.

Ó Dochartaigh, Cathair (ed.). 1997. Survey of the Gaelic dialects of Scotland. Dublin: Dublin Institute for Advanced Studies.

Ó Duibhir, Pádraig \& Jill Garland. 2010. Gaeilge labhartha na bpáistí i scoileanna lán-Ghaeilge in Éirinn [The spoken Irish of pupils in Irish-medium schools in Northern Ireland]. Armagh: SCoTENS.

Ó Giollagáin, Chonchúr, Seosamh Mac Donnacha, Fiona Ní Chualáin, Aoife Ní Shéaghda \& Mary O’ Brien. 2007. Comprehensive linguistics study of the use of Irish in the Gaeltacht: Principal findings and recommendations. Dublin: Department of Community, Rural and Gaeltacht affairs. 
Oftedal, Magnus. 1956. A linguistic survey of the Gaelic dialects of Scotland. Vol III: The Gaelic of Leurbost, Isle of Lewis. Oslo: Norsk Tidsskrift for Sprogvidenskap.

O’Hanlon, Fiona, Wilson McLeod \& Lindsay Paterson. 2010. Gaelic-medium Education in Scotland: Choice and attainment at the primary and early secondary school stages. Inverness: Bòrd na Gàidhlig.

O’Rourke, Bernadette \& Joan Pujolar. 2015. Introduction to special issue 'New speakers and processes of new speakerness across time and space'. Applied Linguistics Review 6(2), 145-150.

O’Rourke, Bernadette, Joan Pujolar \& Fernando Ramallo. 2015. Introduction to special issue 'New speakers of minority languages: The challenging opportunity'. International Journal of the Sociology of Language 231(1), 120.

O’Rourke, Bernadette \& Fernando Ramallo. 2013. Competing ideologies of linguistic authority amongst new speakers in contemporary Galicia. Language in Society 42, 287-305.

Ortega, Ane, Estibaliz Amorrortu, Jone Goirigolzarri, Jacqueline Urla, Belen Uranga. 2014. New Basque speakers: Linguistic identity and legitimacy. Digithum 16, $47-58$.

Puigdevall, Maite. 2014. Introduction to special issue 'New speakers of minority languages: Belonging and legitimacy'. Digithum 16, 44-46.

Quist, Pia. 2008. Sociolinguistic approaches to multiethnolect: Language variety and stylistic practice. International Journal of Bilingualism 12(1), 43-61. 
Rathcke, Tamara, Jane Stuart-Smith, Claire Timmins \& Brian José. 2012. Trying on a new BOOT: Acoustic analyses of real-time change in Scottish English. Poster presented at NWAV 41, 26th October 2012.

Ravid, Dorit Diskin. 1995. Language change in child and adult Hebrew: A psycholinguistic perspective. Oxford: Oxford University Press.

Shuken, Cynthia. 1980. An instrumental investigation of some Scottish Gaelic consonants. Ph.D. thesis, University of Edinburgh, Edinburgh.

Siegel, Jeff. 1985. Koines and koineization. Language in Society 14, 357-378.

Stuart-Smith, Jane. 1999. Glasgow: Accent and voice quality. In Paul Foulkes \& Gerald Docherty (eds.) Urban voices: Accent studies in the British Isles, 203223, London: Arnold.

Ternes, Elmar. 2006. The phonemic analysis of Scottish Gaelic. Dublin: Dublin Institute for Advanced Studies, 3rd edn.

Traunmüller, Hartmut. 1990. Analytical expressions for the tonotopic sensory scale. Journal of the Acoustical Society of America 88, 97-100.

Trudgill, Peter. 2004. New dialect formation: The inevitability of Colonial Englishes. Edinburgh: Edinburgh University Press.

Wells, John. 1982. Accents of English. Cambridge University Press.

Wiese, Heike. 2009. Grammatical innovation in multiethnic urban Europe: New linguistic practices among adolescents. Lingua 119, 782-806.

Withers, Charles. 1998. Urban Highlanders: Highland-Lowland migration and urban Gaelic culture, 1700-1900. East Linton: Tuckwell. 